\title{
РОЛЬ ГОСУДАРСТВА В ПОВЫШЕНИИ ЭФФЕКТИВНОСТИ ДЕЯТЕЛЬНОСТИ СЕЛЬСКОХОЗЯЙСТВЕННЫХ ОРГАНИЗАЦИЙ
}

\author{
(c) 2021 Жиляков Дмитрий Иванович
}

кандидат экономических наук, доцент, кафедра бухгалтерского учета и финансов

Курская государственная сельскохозяйственная академия имени И.И.Иванова, Россия, Курск

E-mail: zhilyakov@yandex.ru

В статье определена актуальность исследования финансовых результатов деятельности сельскохозяйственных организаций, проведен анализ динамики численности прибыльных и убыточных предприятий. На основании расчета удельного веса прибыльных и убыточных организаций, их соотношения определены проблемы функционирования аграрных предприятий и определена роль государства в их решении.

Ключевые слова: финансовые результаты, прибыль, убыток, финансы, эффективность деятельности, государственное регулирование.

Построение эффективной системы государственного регулирования невозможно без рентабельного функционирования сельскохозяйственных организаций. Поэтому анализ финансового состояния сельскохозяйственных организаций, и связанное с данным направлением изучение влияния государственной поддержки, является необходимым элементом научных исследований в данной области.

В условиях формирования рыночных отношений важным показателем развития аграрной отрасли являются финансовые результаты деятельности сельскохозяйственных организаций, которые проявляются в виде получения прибыли или убытков. В условиях рыночной экономики и свободной конкуренции цель предприятия в виде ведения прибыльной деятельности объективно предопределена, т.к. наличие и рост прибыли отражает повышение эффективности производства продукции, рост ее качества и востребованности на рынке, снижения ее себестоимости, повышение эффективности использования трудовых, земельных и финансовых ресурсов. Эффективное управление финансовыми результатами является необходимым условием стабильной деятельности организации любой, в том числе аграрной отрасли.

Интерес к финансовым результатам деятельности организации проявляется со стороны широкого круга лиц [20]:

- собственники предприятия, т.е. лица, предоставившие собственные финансовые ресурсы при создании организации;

- заемщики, т.е. лица, предоставляющие свой капитал за плату во временное пользование на краткосрочной и долгосрочной основе;

- управленческий персонал организации, т.е. лица, осуществляющие непосредственное руководство деятельностью предприятия;

- контрагенты организации, которые предоставляют свои финансовые ресурсы предприятию на срочной, возвратной и платной основе;

- государство в лице налоговых органов, рассматривающих финансовый результат как базу для налогообложения.

Наряду с этим государство является заинтересованным лицом не только в силу необходимости выполнения фискальной функции и обеспечения наполняемости бюджета, но и ввиду необходимости эффективного развития определенных приоритетных отраслей экономики. Современные достижения в области объемов производства сельскохозяйственной продукции [9] и роста продовольственной безопасности страны, не нивелируют ряд существующих нерешенных проблем в отрасли, при этом некоторые их них продолжают усугубляться. Одной из таких проблем остается невысокая прибыльность, а зачастую убыточность сельскохозяйственного производства [19]. На фоне развития аграрной отрасли в настоящее время и роста производства сельскохозяйственной продукции мы видим снижение прибыли, получаемой сельскохозяйственными организациями - таблица 1.

Несмотря на то, что численность прибыльных организаций снижалась достаточно существенными темпами - с 13,2 тыс. в 2004 году до 4,9 тыс. в 2010 году и до 2,9 тыс. в 2019 году, их 


\begin{tabular}{|c|c|c|c|c|c|c|c|c|}
\hline \multirow{3}{*}{ 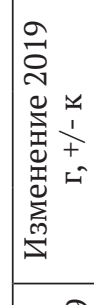 } & \begin{tabular}{c|c}
$\infty$ & -1 \\
$\stackrel{0}{0}$ & 0
\end{tabular} & $\stackrel{0}{i}$ & $\begin{array}{c}\infty \\
i \\
i\end{array} \mid$ & $\overbrace{0}^{0}$ & $\cong$ & 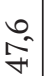 & $\underset{i}{\stackrel{2}{7}}$ & $\overrightarrow{0}$ \\
\hline & 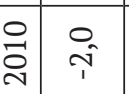 & $\stackrel{\infty}{n^{\infty}}$ & $\vec{a}$ & $\stackrel{0}{i}$ & $\begin{array}{l}\infty \\
\hat{p}^{n}\end{array}$ & $\begin{array}{l}m \\
m \\
00^{-1} \\
=1\end{array}$ & 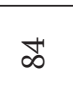 & $\stackrel{m}{\rightarrow}$ \\
\hline & 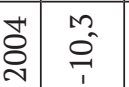 & $\begin{array}{l}0 \\
\stackrel{-}{=}\end{array}$ & $\mid$ & $\vec{F}$ & $\begin{array}{l}0 \\
\stackrel{5}{1} \\
1\end{array}$ & $\begin{array}{l}N_{2} \\
\\
=\end{array}$ & กิ & $\stackrel{\infty}{i}$ \\
\hline$\stackrel{\text { จे }}{\circ}$ & $\hat{\sigma}$ & $\ddot{\infty}$ & \begin{tabular}{|l|}
$\infty$ \\
$\hat{0}$ \\
0
\end{tabular} & $\hat{0}$ & $\begin{array}{l}0 \\
0 \\
a\end{array}$ & $\begin{array}{l}0 \\
\vdots \\
\dot{y}\end{array}$ & $\begin{array}{l}\infty \\
\text { ñ }\end{array}$ & $\vec{f}$ \\
\hline$\stackrel{\infty}{\stackrel{\infty}{\circ}}$ & $\stackrel{\infty}{\sim}$ & $\stackrel{+}{\Leftrightarrow}$ & $\begin{array}{l}0 \\
0 \\
8\end{array}$ & $\hat{o}$ & $\begin{array}{l}+4 \\
\infty \\
\rightarrow\end{array}$ & $\begin{array}{l}+ \\
2 \\
2\end{array}$ & ז̊̊ & $\stackrel{\circ}{+i}$ \\
\hline 공 & $\hat{i}$ & $\begin{array}{l}\text { ma } \\
\text { ấ }\end{array}$ & 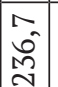 & $\begin{array}{l}0 \\
0 \\
0\end{array}$ & 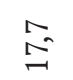 & $\begin{array}{l}n \\
0 \\
\text { in } \\
\text { in }\end{array}$ & 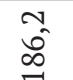 & $\stackrel{n}{*}$ \\
\hline 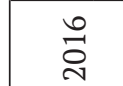 & $\stackrel{M}{m}$ & $\stackrel{+}{+}$ & $\mid$ & $\begin{array}{l}0 \\
0 \\
0\end{array}$ & $\begin{array}{l}0 \\
\text { in } \\
\end{array}$ & $\begin{array}{l}0 \\
0 \\
f \\
f\end{array}$ & 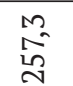 & $\begin{array}{l}\text { in } \\
\text { in }\end{array}$ \\
\hline$\stackrel{n}{\stackrel{n}{0}}$ & $\hat{n}$ & $\vec{\infty}$ & $\begin{array}{l}\hat{0} \\
\mathrm{~m} \\
\mathrm{~N}\end{array}$ & $\stackrel{\infty}{0}_{0}^{\infty}$ & $\hat{\sigma}$ & $\begin{array}{l}0 \\
0 \\
i n\end{array}$ & $\overrightarrow{0}$ & $\stackrel{0}{+}$ \\
\hline$\underset{\sim}{\stackrel{H}{~}}$ & $\begin{array}{l}\infty \\
n^{-}\end{array}$ & $\hat{\infty}$ & 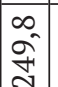 & $\stackrel{0}{-}$ & $a^{2}$ & $\begin{array}{l}\text { in } \\
\text { no } \\
\text { nn }\end{array}$ & $\stackrel{m}{m}$ & $\stackrel{\infty}{\stackrel{\infty}{n}}$ \\
\hline$\stackrel{m}{\stackrel{n}{a}}$ & & $\stackrel{⿱ 亡}{\stackrel{2}{N}}$ & $\vec{a}$ & $\Rightarrow$ & $\begin{array}{l}0 \\
\text { â }\end{array}$ & $\stackrel{\sim}{-}$ & 京 & $\stackrel{0}{m}$ \\
\hline$\stackrel{\sim}{\stackrel{\Upsilon}{9}}$ & $\stackrel{m}{f}$ & 点 & $\begin{array}{l}\hat{\sigma} \\
\hat{n}\end{array}$ & $\cong$ & $\stackrel{\mathfrak{M}}{\text { Â }}$ & $\begin{array}{l}m \\
\hat{N}\end{array}$ & $\stackrel{H}{n}$ & $\stackrel{0}{m}$ \\
\hline $\overrightarrow{\vec{\sigma}}$ & $\stackrel{\infty}{+}$ & $\begin{array}{l}0 \\
\infty\end{array}$ & 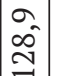 & $\stackrel{\sim}{\sim}$ & Oे & $\begin{array}{l}\infty \\
- \\
n \\
\end{array}$ & 웅 & $\stackrel{0}{\circ}$ \\
\hline$\stackrel{\circ}{\circ}$ & $\stackrel{\sigma}{\sigma^{\prime}}$ & $\stackrel{0}{\stackrel{+}{N}}$ & $\hat{0}$ & 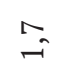 & 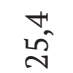 & 管 & 0 & $\hat{\sigma}$ \\
\hline oิ & in & $\stackrel{\infty}{t}$ & $\begin{array}{l}m \\
2 \\
2\end{array}$ & $\stackrel{\infty}{-}$ & กิ & \begin{tabular}{l}
$n$ \\
\multirow{2}{N}{} \\
\end{tabular} & $\begin{array}{l}\infty \\
i n \\
0\end{array}$ & $\hat{\sigma}$ \\
\hline$\stackrel{8}{\circ}$ & $\begin{array}{l}0 \\
0\end{array}$ & $\stackrel{0}{0}$ & $\mid$\begin{tabular}{l} 
\pm \\
\multirow{2}{*}{} \\
0
\end{tabular} & $\stackrel{n}{=}$ & $\begin{array}{l}+ \\
\infty \\
\infty\end{array}$ & ָ̊ & $\hat{\sigma}$ & $\stackrel{+}{*}$ \\
\hline ๖్ & $\stackrel{\approx}{\approx}$ & 全 & \begin{tabular}{|l|}
$\infty$ \\
$\mathbb{0}^{+}$ \\
\end{tabular} & $\tilde{n}^{-}$ & $\stackrel{\text { ân }}{\text { N̂}}$ & $\begin{array}{l}m \\
\stackrel{m}{2}\end{array}$ & $\begin{array}{l}n= \\
\infty \\
\infty\end{array}$ & in \\
\hline \& & $\stackrel{0}{=}$ & m & $\vec{m}$ & बे & 部 & 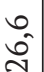 & $\begin{array}{l}\text { in } \\
\text { ô }\end{array}$ & $\stackrel{g}{\rightarrow}$ \\
\hline 옹 & $\stackrel{0}{=}$ & m & $\begin{array}{c}0 \\
\text { in } \\
\text { in }\end{array}$ & $\stackrel{M}{N}$ & $\hat{m}$ & $\begin{array}{l}n \\
\text { הิ }\end{array}$ & in & $\stackrel{n}{\rightarrow}$ \\
\hline 苍 & $\stackrel{\sim}{\sim}$ & $\begin{array}{l}\infty \\
\text { đิ }\end{array}$ & $\begin{array}{l}\text { in } \\
\text { กิ }\end{array}$ & $\stackrel{\infty}{\sim}$ & $\stackrel{N}{\stackrel{N}{M}}$ & $\begin{array}{c}\infty \\
\stackrel{\infty}{N}\end{array}$ & 茯 & $\approx$ \\
\hline 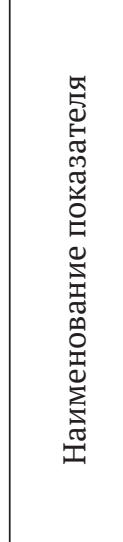 & 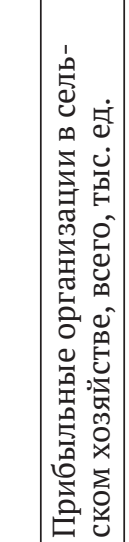 & 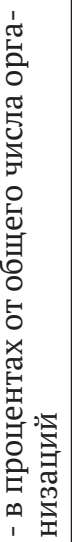 & 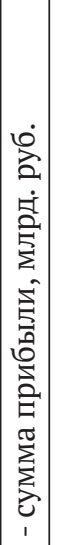 & 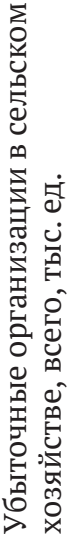 & 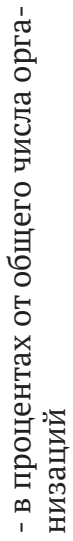 & 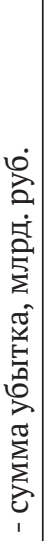 & 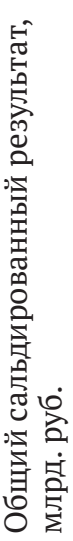 & 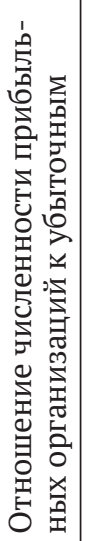 \\
\hline
\end{tabular}

удельный вес в общей численности предприятий увеличивался в течение анализируемого периода. В данном случае, очевидно, что действие рыночных законов обоснованно приводит к снижению доли неэффективных предприятий, они банкротятся или объединяются с более крупными, эффективными организациями. Одновременно следует отметить сокращение убыточных организаций как в абсолютном выражении - с 7,8 тыс. в 2004 году до 1,7 тыс. в 2010 году и до 0,7 тыс. в 2019 году, так и в относительном - с $37,2 \%$ в 2004 году до $25,4 \%$ в 2010 году и до $19,6 \%$ в 2019 году. В результате отмеченных тенденций отношение численности прибыльных организаций к убыточным возросло с 1,7 в 2004 году до 2,9 в 2010 году и до 4,1 в 2019 году.

Данная динамика позволяет сделать вывод о том, что кризисные явления в аграрной отрасли в определенной степени преодолены, и в настоящее время происходит повышение эффективности деятельности сельскохозяйственных организаций и численности прибыльных предприятий.

В то же время следует отметить, что рост удельного веса прибыльных организаций носит нестабильный характер. Во-первых, на фоне роста в целом за анализируемый период выделяются 2005, 2009-2010, 2012-2013 годы, когда отмечалось его снижение, а во-вторых, достигнув максимума в 2016 году $(84,4 \%)$ данный показатель стабильно снижается.

Это позволяет сделать вывод, что как в производственной, так и в финансовой сфере в аграрной отрасли страны не достигнута стабильность, и аграрные предприятия, в целом развиваясь и повышая финансовые результаты, по-прежнему работают в сложных условиях, не обеспечивающих получения стабильной прибыли и по причине неблагоприятных погодных условий (2010 и 2017 годы), и по причине изменения рыночной конъюнктуры (2005, 2012-2013 годы) и системных экономических условий (2017-2019 годы).

Данный вывод подтверждается негативной динамикой снижения суммы прибыли, полученной организациями аграрной отрасли в 2005 , 2009, 2013 и 2016-2019 годах.

На фоне незначительного колебания финансовых результатов особенно выделяются последние годы. Если в 2015 году сумма прибыли составила 330,7 млрд. рублей, то в 2016 году она снизилась до 300,9 млрд., а к 2017 году отмеча- 
ется еще более значительное сокращение - до 236,7 млрд. руб. Общее снижение составило 94 млрд. рублей. При этом снижение суммы полученных сельскохозяйственными организациями убытков не позволило компенсировать снижение прибыли, поэтому общий сальдированный результат также сократился - с 280,1 млрд. рублей в 2015 году до 257,3 млрд. руб. в 2016 году и до 186,2 млрд. руб. в 2017 году.

В 2018 и 2019 годах ситуация в определенной степени улучшилась, и суммы прибыли составили 300,0 млрд. и 302,8 млрд. рублей соответственно. Но при этом существенно возросли суммы полученных убытков - до 95,4 млрд. рублей в 2018 году и до 143,0 млрд. в 2019 году. Учитывая, что современные организации, работающие в агарной отрасли - частные и основной целью их деятельности является получение прибыли, можно говорить о том, что данная ситуация не позволяет им достигать поставленных целей. Одновременно следует отметить, что прибыль в современной экономике является одним из основных источников инвестиций, обеспечивающих дальнейшее развитие предприятий, и ее снижение свидетельствует не только о снижении эффективности текущей деятельности аграрных предприятий, но и о снижении финансовых возможностей для обеспечения их дальнейшего развития.

Иными, словами, сложившаяся ситуация не только отражает текущее ухудшение в сельскохозяйственной отрасли, но и свидетельствует о снижении потенциальных возможностей для ее развития в будущем.

Выявленные тенденции вызывают необхо- димость повышенного внимания к финансовым результатам деятельности организаций агропромышленного комплекса и совершенствования направленных на их поддержку мероприятий по обеспечению прибыльности и развитию сельскохозяйственной отрасли $[5,6]$.

Следует отметить, что государство в лице регулирующего органа также заинтересовано в прибыльной деятельности сельскохозяйственных организаций. Прибыльные предприятия имеют возможности осуществления инвестиций, наращивания объемов производства продукции, увеличения количества рабочих мест и обеспечение роста заработной платы сотрудников. Все это обеспечивает дальнейшее развитие агропромышленного комплекса, повышение продовольственной безопасности страны, выполнение социальной функции государства.

Необходимо отметить, что на прибыль влияет значительное число внешних факторов, на которые предприятие не всегда может воздействовать. Поэтому применяемые методы государственного регулирования должны быть направлены как на обеспечение условий прибыльной и эффективной деятельности сельскохозяйственных организаций, так и на поддержку и развитие эффективных производств в целях дальнейшего развития отрасли. Приоритетным направлением должно быть не увеличение субсидирования сельхозтоваропроизводителей, а формирование условий работы в интересах частного бизнеса и государства, что будет способствовать устойчивому развитию аграрной отрасли и обеспечению продовольственной безопасности страны.

\section{Библиографический список}

1. Водолазская Н.В. Инновационный подход к обеспечению устойчивого развития организационно - экономических систем. [Текст] // Органическое сельское хозяйство: проблемы и перспективы: материалы XXII Международной научно-производственной конференции (п. Майский, 28-29 мая 2018 г.): в 2 т. Т. 1.п. Майский: Белгородский ГАУ, 2018.- С 51-53.

2. Водолазская Н.В. О тенденциях устойчивого развития региональных производственных систем / Н. В. Водолазская // Проблемы и решения современной аграрной экономики. XXI международная научнопроизводственная конференция.-2017.-С. 186-187.

3. Жиляков, Д.И. Динамика и роль финансовых результатов деятельности организаций АПК в развитии отрасли [Текст] / Жиляков Д.И.// Вклад университетской аграрной науки в инновационное развитие агропромышленного комплекса. Материалы 70-й Международной научно-практической конференции. Министерство сельского хозяйства РФ, Рязанский государственный агротехнологический университет им. П.А. Костычева. - 2019.- С. 247-252.

4. Жиляков, Д.И. Анализ состояния мирового рынка пшеницы и перспективы России по расширению экспортного потенциала [Текст] / Д.И. Жиляков, В. Я. Башкатова, Ю. В.Плахутина и др. // Экономические науки. - 2020. - № 183. - С. 38-43. 
5. Жиляков, Д.И. Влияние государственной поддержки на финансовые результаты деятельности сельскохозяйственных предприятий [Текст] / Д. И. Жиляков // Материалы Международной научно-практической конференции «Интеграция науки и сельскохозяйственного производства».-2017.- С. 317-320.

6. Жиляков, Д. И. Оценка динамики и эффективности государственной поддержки АПК [Текст] / Д. И. Жиляков // Материалы международного молодежного аграрного форума «Аграрная наука в инновационном развитии АПК».- 2018. - С. 56-61.

7. Зарецкая В.Г. Диверсификация экономики российских регионов: измерения и тенденции / В.Г Зарецкая., И. К. Титкова // Национальные интересы: приоритеты и безопасность. - 2017. - Т. 13. -№ 12 (357).- С. $2236-2255$.

8. Зарещкая В.Г. Эволюция финансовой отчетности в Российской Федерации и ее влияние на процедуру анализа финансового состояния // Международный бухгалтерский учет. - 2011. - № 34 (184). - С. 33 -38.

9. Зюкин, Д.В. Основные тенденции развития сельскохозяйственной отрасли Курской области на современном этапе [Текст] / Д. В. Зюкин, О. С. Косинова // Наука и практика регионов. - 2018. - № 1 (10). - С. 42-46.

10. Котляров, И.Д. Вертикально кооперированные агропромышленные организации в сельском хозяйстве стран СНГ [Текст] / И.Д.Котляров // Международный научно-производственный журнал «Экономика АПК».-2016. - № 10 (264).- С. 89-94.

11. Котляров, И.Д. Формирование вертикально кооперированных агропромышленных объединений в сельском хозяйстве стран СНГ [Текст] / И. Д. Котляров // Островские чтения. 2016. № 1. С. 128-132.

12. Петрушина О.В. Концептуальные подходы к ресурсному обеспечению развития зернового комплекса: финансы государства / О.В.Петрушина // Экономика и предпринимательство.- 2020. - № 5 (118). - С. $523-$ 526.

13. Петрушина, О. В. Сущность и необходимость анализа финансового состояния предприятия [Текст] / О. В. Петрушина, А. В.Гололобова // Международной научно-практической конференции студентов, аспирантов и молодых ученых «Инновационная деятельность в модернизации АПК». - 2017.- С. 118-122.

14. Пронская, О.Н. Теоретико-методологические основы воспроизводства в сельском хозяйстве [Текст] / О.Н.Пронская, О.С. Фомин О.С. // Сборник статей «Закономерности и тенденции развития оценки, управления, учета и нормативно-правового обеспечения финансовой системы России» Москва. - 2017.- С. 5659.

15. Плахутина Ю.В. Государственное регулирование воспроизводственного процесса в сельскохозяйственных организациях / Ю. В.Плахутина // Государство и общество: вчера, сегодня, завтра. Серия: Экономика.2012.- № 6 (2). - С. 66-79.

16. Соклаков А.А. Основные направления совершенствования государственного регулирования сельского хозяйства в Курской области / А. А. Соклаков, Е. С. Малыхина // Современные подходы к трансформации концепций государственного регулирования и управления в социально-экономических системах. - 2019. - С. 128-131.

17. Соколов О.В. Оценка деловой активности и рентабельности деятельности организации / О.В.Соколов, М. О.Пашигорева // Наука и Образование. - 2018. - Т. 1. - № 2.- С. 15.

18. Соколов О. В. Факторы формирования прибыли предприятия / О.В. Соколов, А. А. Трофимова // Продовольственная безопасность в условиях международных санкций. Мичуринск.-2017. - С. 207-211.

19. Соловьева, Т.Н. Маржинальный анализ прибыли птицефабрик яичного направления Курской области [Текст] / Т. Н. Соловьева, Д. И. Жиляков // Экономика сельскохозяйственных и перерабатывающих предприятий. - 2007. - № 7.- С. 60-62.

20. Широбоков, В.Г. Управление финансовыми результатами предприятий АПК в рамках стейкхолдерского подхода [Текст] / В.Г.Широбоков, А. В. Воронков // Материалы научно-практической конференции, посвященной 100-летию со дня создания кафедры организации производства и предпринимательской деятельности в АПК «Современные организационно-экономические проблемы развития АПК.-2015.- С. 183-187. (C. 184) 